\title{
The Importance of Result Based Management (RBM) and Challenges NGOCC Member Organisations Face in the RBM
}

\author{
Article by Mwale Nelson Kusensio \\ Master of Science in Management by Research, Texila American University, Zambia \\ Email:mwalenelson@yahoo.com
}

\section{Introduction}

Chapter one has focused on giving background of the study, significance, research objectives and questions, and limitation of the study. Furthermore, this chapter has provided statement of the problem upon which the research study has been anchored.

\section{Background}

Non-Governmental Organisations (NGOs) are generally considered to be playing an increasingly important role in international and national development. The ongoing support given to NGO's by international and national donors can be seen as evidence that they are considered to be more effective than state-owned organisations in implementing and sustaining developmental programmes. It has further been seen that NGOs and their operations have been influenced by the "New Policy Agenda" which according to Edwards and Hulme (2000) is characterised by two theories. The first implies that NGOs have been enabled by governments to be private providers because of their supposed cost-effectiveness and their ability to more effectively reach the masses in remote areas where the government (public sector) cannot reach.

The second suggests that since NGOs are vehicles for democratisation they have a fundamental humanitarian role to fulfill which should counterbalance state power, protect human rights, open up communication channels and participation, and promote activism and pluralism. NGOs also play a critical role in building state accountability through lobbying for legislation on transparency, adherence to international commitments on human rights; monitoring and evaluation of government programmes through social audits and or participatory expenditure tracking system; and demanding answers from the states by questioning state institutions about the progress being made on the implementation of certain issues.

For instance in Zambia, NGOs which focus on governance issues question the state institutions such as Office of Auditors General and Anti-Corruption Commission about the steps or actions which are being taken against the individuals and public institutions with regards to mismanagement of public financial resources raised in the Auditors report on public expenditure for various government ministries.

More importantly NGOs play a critical role in building state responsiveness through identification and voicing the needs of vulnerable and marginalised citizens in the country. It is from this angle that NGOs are fundamentally different from state institutions in the program implementation and service delivery to the people in the communities. It not disputable that NGOs reach and provide services to the most vulnerable people in remote areas where government does not reach; and promote participation of the poor people in development process to take greater control over their own lives rather than an outcome of particular projects and or programmes (Norad, 2008).

The above stated roles of NGOs have led to the mushrooming of new ones, for instance Zambia had about 10,000 registered Civil Society Organisations in 2003. Furthermore, the adoption of the "New Policy Agenda" has motivated NGOs to scale-up their operations and programmes (Edwards \& Hulme 2000). Arguably, NGOs are considered to be vehicles for "democratisation" hence they have become the preferred channel for service provision and the role of government organisations in development processes has often been deliberately 
replaced. The growth and increase in number of NGOs in the recent years has, however, also meant increased competition for donor funding Ebrahim et al (2010) and the need for greater accountability and visibility not only at the local constituency level, but also internationally.

All the above factors as well as external factors such as the fast changing environment and increased globalisation have made the management of NGO operations very complex. This has forced the donors to adopt and introduce results-based management (RBM) to improve the effectiveness and accountability in the management, operations and implementation of programmes of NGOs. The RBM system is based on what is commonly referred to as a 'life cycle' where 'results' are central to planning, implementation, monitoring and evaluation, reporting and ongoing decision-making (Hailey and Sorgenfrei, 2004). By focusing on 'results' rather than 'activities', RBM helps NGOs to better articulate their programs and support for expected results and to better monitor progress using indicators, targets and baselines.

Results based reports also help the organisation(s), stakeholders and funders to better understand the impact that a given programme or project is having on the local population. NGOs have been striving harder to employ RBM procedures and principles in the programming. However, not all NGO's have been equally successful at embracing ResultsBased Management principles (Norad, 2008). There is often skepticism and inadequate capacities and skills with regard to the effectiveness of results-based management practices among NGOs.

\section{Problem Statement}

The donors have introduced the results-based management (RBM) to improve the effectiveness and accountability in the management, operations and implementation of programmes by NGOs (Norad, 2008). The results-based management has become mandatory among NGOs if they want to receive funding from potential donor/or funders. Mostly if not always the international and local donors in Zambia such as United States Agency for International Development (USAID), Zambian Governance Foundation (ZGF), Churches Association of Zambia (CHAZ) to mention but a few usually demand for established Monitoring and Evaluation system if the applied program is to be funded. In simple terms results-based management through Monitoring and Evaluation is one of the conditionality's which most donors have put in place for NGOs to access the funding.

To the donors the introduction of results-based management is one way of promoting efficiency, effectiveness and holding the NGOs accountable to the resources awarded to them to achieve the results planned for in the project/or program. However results-based management practices among NGOs are generally believed to be ineffective due to the adoption of the wrong RBM strategies, particularly when inappropriately copied from other organisations and start being operationalised without taking into account of the existing knowledge level and skills among the existing staff (Britten 1998). It is not clear whether the importance of results-based management approach has been clearly explained to NGOs so that they can strive harder to incorporate them into programs at the inception.

- Furthermore, it is not clear about the challenges which NGOs face to implement the results-based management approach, and the support which donors provide to NGOs for them to effectively implement the results-based management approach is not known. All the factors discussed above have prompted the need to undertake this research study. Therefore, the aim of this research study is to investigate and understand the importance of the Result Based Management (RBM) in the Project Management and the Challenges Non Governmental Organisations' Coordinating Council (NGOCC) Member Organisations (Non-Governmental Organisations-NGOs and Community Based Organisations) face in the RBM. 


\section{Objectives of the Study}

\section{General Objective}

- To investigate and understand the importance of the Result Based Management (RBM) in the Project Management and the Challenges NGOCC Member Organisations (Non-Governmental Organisations-NGOs and Community Based Organisations) face in the RBM.

\section{Specific Objectives}

- To investigate the extent to which the donors have explained to NGOCC Member Organisations the importance of results-based management and the support which donors provide to NGOs to strengthen results-based management;

- To determine the extent to which NGOCC Member Organisations understand the importance of results-based management in their programs;

- To identify the challenges faced by NGOCC Member Organisations in the resultsbased management and interventions/recommendations to donors and NGOCC Member Organisations to help them improve their results-based management.

\section{Research Questions}

- To what extent do the NGOCC Member Organisations understanding on the importance of results-based management in the project management?

- What are the challenges faced by NGOCC Member Organisations in the results-based management in the project management?

- What support do donors provide to NGOCC Member Organisations to strengthen results-based management?

- What interventions should NGOCC Member Organisations and donors put in place to strengthen the results-based management;

\section{Significance of the Research Project}

- Findings of the research may help the donors (international and local)to understanding the support to provide NGOs to improve the results-based management in programming;

- The findings of the research would help NGOCC Member Organisations to understand the importance of results-based management in their projects they implement so that they strive harder to institutionalise the results-based management processes in their programming;

- These findings may help NGOs to design or come up with interventions to help them improve the results-based management of their projects they implement hopefully with the benefit of improving the performance of the projects and their accountability to the stakeholders in terms of resource use and impact of the projects they implement;

- Finally, this research study is very important for my program of study to be awarded a Master of Science in Management by Research at Texila American University.

\section{Literature Review}

\section{Definition of Concepts}

\section{NGOs}

Non-Governmental Organisations (NGOs) are defined differently by different individuals and there is no single agreed upon definition. NGOs are charitable and religious organisations that mobilise private funds for development, deliver services to the communities through community participation and involvement to improve the quality of life for people. However in this research study, NGOs will be defined as groups and institutions that are entirely or 
South American Journal of Management

Special Edition 2016

largely independent from the government, and they are primarily humanitarian or non-profit making organisations (Edwards and Hulme, 2000).

\section{Results-Based Management, and Monitoring and Evaluation}

\section{Need for monitoring}

Monitoring is the routine continuous tracking of the key elements of project implementation performance that is: inputs (resources, equipment etc) activities and outputs, through recordkeeping and regular reporting (McCoy et al., 2005). It seeks to determine if the inputs, activities and outputs (immediate deliverables) are proceeding according to plan. Inputs to be tracked include financial resources, human resources, equipment used on the project and any other input that goes into project implementation. The financial resources are tracked with a budget and performance is analyzed by comparing planned expenditure against actual expenditure. Activities or processes are tracked using a schedule, which is planned schedule against actual schedule of the activities i.e. what activities have been done versus what should have been done according to the planned schedule.

Crawford and Bryce (2003) argued that monitoring is an ongoing process of data capture and analysis for primarily project control with an internally driven emphasis on efficiency of project. The authors define efficiency in this context as doing the right thing that is: efficient conversion of inputs to outputs within budget and schedule and wise use of human, financial and natural capital. This definition emphasizes the fact that monitoring is geared mainly to project control. This is in agreement with the operational definition that looks at project control as taking corrective action and making decisions pertaining to the project by the project manager during implementation.

Uitto (2004) defines monitoring briefly as a continuous function that aims primarily to provide management and stakeholders with early indicators of project performance of a project and progress (or lack thereof) in achievement of the results. Monitoring is seen as a continuous function as highlighted in the contextual definition of this research but it does not highlight what is tracked against what so as to be able to indicate performance. Nevertheless it emphasizes the fact that monitoring is very important in that it provides information to the management and stakeholders about performance. It also highlights the fact that monitoring is results oriented.

Tracking the planned implementation against the actual implementation is important in order to able to report on how the project is progressing and if there is need for corrective action and to facilitate decision making by the project manager during implementation (McCoy et al., 2005). Therefore there is need to determine whether the resources provided by the donors are being used efficiently and effectively, whether the projects are within schedule and to determine any problems that may be hampering the implementation. Determination of efficient management of resources is a factor of project monitoring. It is important as highlighted by all the authors above that there is dissemination of the monitoring information to the stakeholders.

The purpose of monitoring in summary is to:

a) Ensure that implementation is moving according to plans and if not the project manager takes corrective action, the control function of project management. The monitoring enhances project management decision making during the implementation thereby increasing the chances of good project performance (Crawford and Bryce, 2003). This function also aids early identification of problems before they get out of hand since it is continuous. This is very important in management of projects as it lessens the chances of crisis management since there is constant feel of the "project temperature".

b) Facilitate transparency and accountability of the resources to the stakeholders including donors, project beneficiaries and the wider community in which the project is implemented. Monitoring tracks and documents resource use throughout the implementation of the project (Crawford and Bryce, 2003). This enhances accountability in that it facilitates the demonstration of the resource use throughout the implementation of the project. 
c) Facilitate evaluation of the project. In a well-designed monitoring and evaluation system, monitoring contributes greatly towards evaluation. Information from monitoring feeds into the evaluation process.

\section{Need for evaluation}

Evaluation is the periodic (not continuous as the case with monitoring usually mid-term and at end of the project) assessment of an ongoing or completed project to determine its actual impact against the planned impact (strategic goal or objectives for which it was implemented) efficiency, sustainability, effectiveness (McCoy et al., 2005). There is also need to determine whether the set objectives were achieved and extent of achievement of the same plus capture any lessons learned from the implementation of the projects to aid future projects. This is a function of project evaluation.

Uitto (2004) argues that evaluations are systematic and independent. They are an assessment of an ongoing or completed project including its design, implementation and results. He further argued that evaluations asses the relevance, efficiency of implementation, effectiveness, impact and sustainability of the project.

Assessing relevance of a continuing project is important to justify continued investment of resources into the project, if found that the project is no longer relevant then funding can be stopped and funds channeled elsewhere. Effectiveness is defined as the extent to which the set project objectives were achieved and efficiency as how economically resources (inputs) were converted into outputs for completed or partially completed projects. While efficiency looks at how the project faired in terms meeting the set schedule and allocated budget.

Sustainability is defined as the continuation of the project to bear benefits to the beneficiaries long after the project has ended or the donors have withdrawn funding. It looks at probability of long-term benefits of project long after the project close (Jody and Ray, 2004). Sustainability is very important in that it is not prudent to have a lot of resources invested in a project whose benefits will be short lived. The design and implementation can be altered in order to increase the chance of sustainability. Sustainability has gained a lot of currency in the recent times, because the donors want to determine whether the project benefits will continue to accrue after they cease financing the project (PASSIA, 2004).

The Organization for Economic Cooperation and Development (OECD) (2002) definition as cited by Jody and Ray (2004) is in agreement with the above definition but adds that an evaluation should provide information that is credible and is useful and can be incorporated into decision making by both the implementers of the project and the donors who financed the project. IFAD (2004) states that evaluations should be as objective as possible so that the information provided is as credible as possible and is not questionable. Objectivity could be achieved by bringing in external consultants that were not involved in the project implementation but who should work in partnership with the project implementation officials. McCoy et al. (2005) are in agreement with other authors and the contextual definitional that evaluation assess the projects effectiveness in achieving its goals and in determining the relevance and sustainability of an ongoing project.

Binnendijk (2000) emphasizes the fact that evaluation compares the project impact with what was set to be achieved in the project plan and further argues that evaluation examines how the project impacts were achieved and what went wrong or right for the benefit of organizational learning. The emphasis of this approach to evaluation is on impact of the project after implementation. It does not recognize the midterm evaluations that tend to look at the continued relevance and sustainability of the project and the impacts that the project has had even before completion. Evaluations can be divided into two types depending on when they take place: formative and summative each is described below in detail.

\section{Formative evaluations}

Formative evaluations take place during the implementation of the project. They are mainly implementation process oriented, reviewing the overall performance of the project in 
terms of input use, schedule of project and outputs. They also look at strengths, weakness, and challenges of the project and whether the continued project plan will be able to deliver the project objectives or it needs redesigning (PASSIA, 2004). This type of evaluation may also look at the continued relevance of the project and its sustainability. The aim is to improve the performance of the project during implementation (Binnendijk, 2000). Formative evaluations are sometimes called interim or midterm evaluations.

\section{Summative evaluations}

Summative evaluations are carried out at the end of the project with objective of determining how the project progressed, what went right and wrong and capture any lessons learned. Summative evaluations may also be able to determine the overall impact of the project and the extent to which the project achieved its objectives (Danida, 2005). Booth et al (2008) identify two types of summative evaluations: processes evaluation and outcome evaluation. A discussion of each follows:

\section{Process evaluations}

Process evaluation is geared towards guiding future projects by facilitating organizational learning. It is not enough to capture whether a project succeeded or not but it is important to understand and document why it succeeded or why it failed so that the mistakes are not repeated and good practices are shared across the stakeholders. Process evaluation also assess how the project faired in terms of efficiency i.e. whether the targeted project outputs were achieved within budget and schedule and if not what the reasons hampered that.

\section{Outcome evaluations}

Outcome evaluation is concerned with the extent to which the set objectives were achieved and how we can attribute the role of project to the outcomes. It is quite hard to clearly attribute that the observed outcomes are solely the result of the project without any other exogenous factor and it is even harder to determine the actual contribution of the project to the observed outcomes. In order to effectively evaluate a project it is important that both the formative and summative evaluations are carried out and with summative evaluation both process and outcome evaluations should be done fully optimize the benefits of evaluation.

\section{Differences between Monitoring and Evaluation}

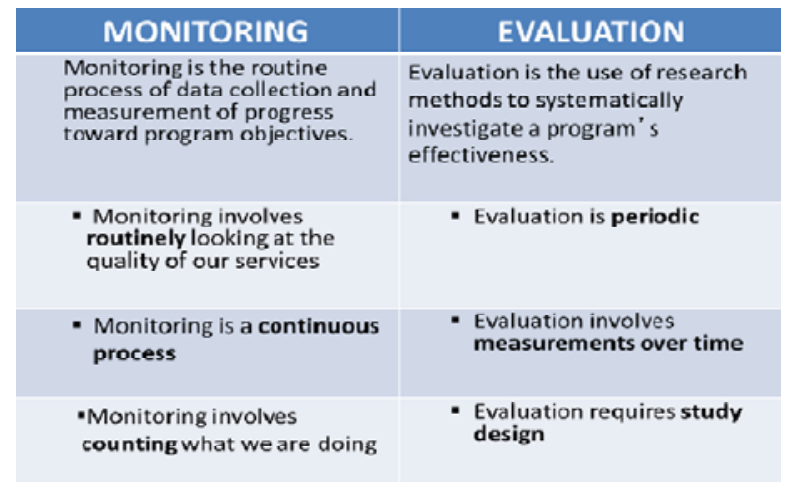

Extract from Hailey and Sorgenfrei (2004)

\section{Results-Based Management}

Results-Based Management (RBM) cannot be separated from monitoring and evaluation, and RBM is achieved when there strong monitoring and evaluation processes in place. In simple term RBM is a management strategy that focuses on performance and the achievement of results (outputs, outcomes and impacts). RBM is also defined as a management strategy aimed at achieving important changes in the way organisations operate, with improving performance in terms of results as the central orientation (Mayne, 2007). RBM provides the 
management framework and tools for strategic planning, risk management, performance monitoring and evaluation.

In 2002 (Forss, et al) argued that the primary purpose of RBM is to improve efficiency and effectiveness through organisational learning, and secondly to fulfill accountability obligations through performance reporting. Key to its success is the involvement of stakeholders throughout the management lifecycle in defining realistic expected results, assessing risk, monitoring progress, reporting on performance and integrating lessons learned into management decisions. Therefore RBM focuses on managing the interventions while trying to ensure its relevance, efficiency, effectiveness, impact and other quality criteria. RBM provides a structured, logical model for identifying expected results and the inputs and activities needed to accomplish them as well as keeping an organization focused on the expected results throughout the process and not on the implementation of activities or on budget control. By being able to measure results, a team will better understand the value of its work.

\section{RBM terminologies}

\section{The results chain}

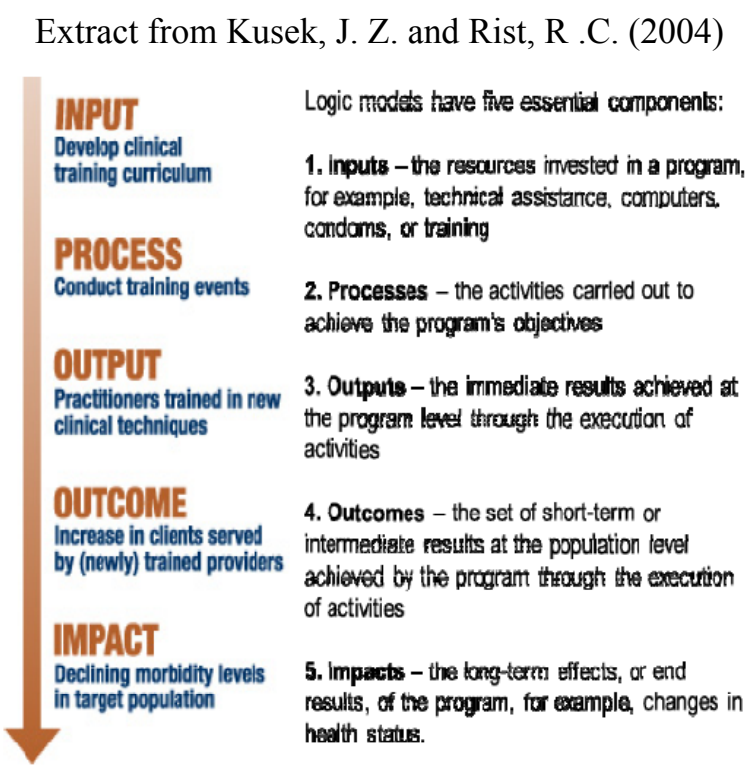

\section{Results}

Results are the effects of an intervention. Such effects can be intended or unintended, positive or negative. There are three levels of results: outputs, outcomes and impacts.

\section{Outputs}

Outputs are the products, capital goods and services that are produced by an intervention, including changes arising from the intervention that are relevant to the achievement of outcomes. Outputs are the first level of results. They are the most immediate effects of an activity, the results over which you have most control.

\section{Outcomes}

Outcomes are the likely or achieved medium-term effects of an intervention's outputs. Outcomes are the second level of results. You have less control over outcomes than over outputs, but they are essential because they represent the tangible changes you are trying to bring about in your work. 
South American Journal of Management

Special Edition 2016

\section{Impacts}

Impacts are the primary and secondary long-term effects of an intervention, be they positive or negative, direct or indirect, intended or unintended. Impacts are the third level of results. They make up the "big picture" of the changes that you are working towards but that your activities alone may not achieve. Impacts represent the underlying goal of your work and justify the intervention.

\section{Analysis of Monitoring and Evaluation in Results-Based Management}

\section{Rational lens}

Programme and operations procedures in most international and national donors are all premised upon results oriented approach, including $M \& E$ systems. In effect, for instance RBM in UNDP is understood as a rational management paradigm that is considered to be objective and geared towards enhancing effectiveness. RBM requires that all processes from goal setting to programme orientation, all components should follow a strict serial leading to organisational and development effectiveness. In addition, as expressed in UNDP's Handbook on Monitoring and Evaluation for Results (2002), monitoring is to capture information and evaluation to provide independent assessment on outcomes and impacts. Thus, the discourse of the agency depicts the use of $\mathrm{M} \& \mathrm{E}$ tools as rational, recognising them as an instrument for organisational learning and management improvement.

In using Results-based M \& E, logic and mechanical models have been adopted in UNDP. The Logical Framework Analysis (LFA), in one form or another, has been widely used in the agency since the 1990s, when it was adopted at the project level. Most procedures now use a various approaches in projects premised on a transformation process from input into activity into output. In addition, Results-based M \& E is integrated into the programme/project cycle. UNDP further understands monitoring as being objective and evaluation as being independent. In this light, the tools are believed to offer informed judgements upon the agency performance that are to guide staff's decisions and interventions. Therefore, the role of and procedures in place for conducting $\mathrm{M} \& \mathrm{E}$ in a context of RBM show the importance and rationality of these systems.

However, there are significant reasons to believe other principles than those of rationality apply. First and foremost, the impact of Results-based M \& E on decision-making is questionable. Presently, there is no sound evidence that information upon results is used in a systematic way to inform adjustments on interventions and operations during the project and/or implementations (UNDP, 2007). Information structure is in place particularly at M \& E centre; however, to produce appropriate knowledge systematically for managerial purposes has remained a major problem. Evidently there is also a persistent lack of good and critical data because it has been mostly limited to comments on the use of inputs and the delivery of outputs as seen so far.

The available data do not only lacks quality, but also fails to provide impartial answers to the results achieved because of interventions. In this regard, it has been observed that the formulation of indicators is contaminated including those indicators which are carefully chosen to measure results in the best possible light. The credibility of measurement and assurance of quality at in most international organisations such as UNDP and local organisation is therefore at stake. Herein, the monitoring of progress of the projects and/or programs does not prove convincing because of managers' subjectivity and lack of good data. Evaluation is neither convincing as judgements seem to be influenced by subjective elements.

Secondly, accountability appears to be prioritised, though UNDP widely proclaims its efforts for advancing a culture of Managing for Development Results (MfDR). Consistent procedures on accountability for results are in place at all levels by means of a comprehensive reporting framework, which has allowed UNDP to reach a top ranking among multilateral organisations in transparency and good governance. In contrast, feedback information mechanisms and/or management response systems for managerial purposes, like the 
mechanism provided by the Evaluation Resource Centre (ERC), are still weak. In this respect, merely two thirds of the independent evaluations issued in 2006 had a management response (UNDP, 2007). This is interesting especially bearing in mind that decentralized evaluations tend to entail even less management responses according to the Executive Board Annual Report on Evaluation of 2007. It is also important to note that even though the reporting framework enables to establish credibility with stakeholders, the absence of comparable information about the impact of other development agencies' interventions hinders reliability.

Overall, decision-making being influenced by performance information is doubtful, thus $\mathrm{M}$ $\&$ E does not serve as an instrumental to use but other uses that cannot be explained through the lens of traditional rationalism. Hence, the rational perspective just partially uncovers the use of Results-based M \& E in UNDP. In this regard, M \& E is simply not feeding objective and independent evidence that shall enable to reach optimal management decisions, but it does offer a prescriptive model based in the analytical structure of the LFA. Rationalism can certainly explain the use of $\mathrm{M} \& \mathrm{E}$ as an action tool that has been integrated into the program cycle in an attempt of enhancing performance and effectiveness.

In effect, the approach has an unquestionable managerial value since it enables UNDP staff to think through the logic of their interventions. As Susan Stout explained, when managers are clear about their objectives and how they will track progress, they tend to perform more effectively than when they do not. Yet, M \& E shall not be understood as the panacea for learning and effectiveness, making rationality the prevailing logic behind its use. Other values need to be incorporated into the understanding of $M \& E$ systems in the context of RBM. In view of offering a comprehensive analysis of the use of results-oriented $M \& E$ in organisations, the political and institutional perspectives will be reviewed to understand various variables.

\section{Political lens}

As earlier stated, Results-based M \& E systems at multilateral organisations such as UNDP engage a variety of stakeholders in relationships where different agendas apply. The system is, thus, heavily influenced by political considerations, which in turn can determine decision and policy making far more successfully than learning.

In the wider context of development aid and grants, different stakeholders participate and expose their concerns throughout the development process. With regard to UNDP, the network of stakeholders is large, especially bearing in mind that the UN is a global association of governments, closely working with civil society organisations and, hence an organisation of multilateral nature. In consequence, UNDP is subject to strong influences, in particular with regard to what should be undertaken, and how and where it should be undertaken. Its development work then becomes a political debate crowded by stakeholders.

It should be stated that multi-layered accountability framework indicates that different groups have different interests with regards to evaluative evidence and information. The accountability framework for results has been therefore premised on a hierarchy of three pillars, namely organisational, programmatic and staff accountability (Berg, 2007). In this respect, the NGOs have been pursuing a corporate agenda of meeting demands from donors for reporting and better financial administration especially at organisational level.

In general, RBM procedures have been centrally-driven and prioritise corporate requirements such as demonstrating accountability and financial soundness. At the programmatic level, the donors' interests for reporting and accountability are of paramount. Meeting reporting commitments is paramount and has become more important than learning to better manage the results. All in all, the staff is more concerned about satisfying reporting requirements to the donors rather than managing the results (UNDP, 2007).

Donors have become more concerned with $\mathrm{M} \& \mathrm{E}$ in program implementation. According to UNDP's evaluation policy introduced in 2006, all interventions should be subject to M \& E. The evaluations are demanded and paid by donors to assess the effectiveness of specific of the projects and program interventions rather than broader development impacts (UNDP, 
2007). If the NGOs who are the beneficiaries of the grants decide the evaluation priorities throughout project cycle, the focus would be on the interventions with an expected positive impact or those about to terminate (Meier, 2003).

Secondly, political tensions interfere in the quality of M \& E. UNDP (2007) denounces that a great bulk of the evaluations conducted are rated as being "highly unsatisfactory" in terms of knowledge on the hows and whys of development interventions. Insufficient monitoring of the outcomes and persistent focus on outputs is a first determinant on the quality of outcome evaluations. In most cases, the reporting system in NGOs frequently disregard comparisons of the results with targets and baselines and, most importantly, to comment on performance indicators.

Starting with the planning phase of the project, very frequently baselines and benchmarks are poor or do not existent, and performance indicators are not specific neither measurable in quantitative terms. Hence staff in most cases avoids comparing results with targets and baselines and discussing quantified results in general, focusing simply on the report and description of inputs, activities and outputs. Overall, it is noted that staff are neglecting to judge on whether results are in fact improving or not and to what extent. For instance, most reports are so broad and descriptive rather than focusing on the performance of projects and programs. It is interesting to note that most NGOs especially senior management is taking corrective measures to improve the definition of indicators, setting of targets and benchmarks, etc. so as to ensure the quality of evaluations.

Therefore, political opposition to provide information on results is evident because of; for example, fear to be held accountable for not having achieved expected results. In this regard, senior managers in NGOs are overall accountable for the formulation, execution, and evaluation of programmes and projects. Consequently, managers only have incentives to commission evaluations of interventions performing well or those programes and projects that donors have decided to stop funding (e.g., because the development discourse has shifted attention towards other interventions, or the contract has come to an end, to mention but a few). Even when external consultants are hired to conduct evaluations, the tendency is to maintain a consensual line with the contracting authority(Taylor, 2005).

On the other hand, it might happen that NGOs staff focuses on what they are being held accountable for, namely output and financial achievements. Even further, managers might not perceive measurement of outcomes as something important they are accountable for. The interests that UNDP and other donors have on the use of Results-based M \& E are closely related to the incentive and reward system currently in place (UNDP, 2001). The features of this system imply that managers and staff should not only focus on quantity and financial achievements, and neglecting the quality of their interventions.

All in all, accountability appears as a main preoccupation for and interest of staff and managers at UNDP and other donors. The drive for accountability explains why staff is assessing output delivery and why they lack motivation to monitor outcomes and impact. In addition, this has a significant influence on how $\mathrm{M} \& \mathrm{E}$ is conducted and information upon achievement of results disclosed. Therefore, political influences subdue performance information and prostrate evaluation findings, making them rather irrelevant for organisational learning even when a use is made for decision making. Herein, the use of Results-based M \& E cannot be merely regarded as instrumental for management improvement and learning, but as a strategic tool that can support and even determine decisions upon an intervention.

Decision processes can be related to continuation, termination, and enlargement of projects and programs. In this regard, the use of $\mathrm{M} \& \mathrm{E}$ is politically set so as to legitimise, defend, or strike a specific development intervention, as well as to drive the allocation of resources. In simple terms Results-based $\mathrm{M} \& \mathrm{E}$ has become a tool and/or instrument which donors use to regulate the funding to recipients or implementers of the programs (NGOs). Therefore, donors can either decide to continue, terminate, or increase the funding so that a project/program can also expand the coverage. Note that the donor continued support and increased funding to the 
organisation is dependent upon the good performance of the organisations in relation to results achieved, as well as the funding focus which the donor is interested in.

From the political perspective, results-oriented evaluations in most donors including UNDP can frequently be understood as holding a persuasive use, i.e. findings set the frame for a debate on a specific intervention. For example, the Results-oriented Annual Report (ROAR) published in 2000 recorded a key finding on the rise of Human Rights as a chief focus in governance support and assistance (IFRC, 2011b). The findings of the report were used to persuade the potential NGOs to applying for funding to focus on Human Rights-based approach to development programming in view of enhancing operational strategies. In such cases it can be argued that evaluation is used to manipulating or persuading people's perception upon which a new intervention or program which a donor is interested in can be developed.

In view of this, one could argue that Results-based $M \& E$ does not only focus on strengthening learning but also enhancing development effectiveness. Political aspects of organisational reality are indeed affecting the implementation and outcome of $\mathrm{M} \& \mathrm{E}$ in most donors and multilateral organisations. While such political influences are clearly observed, it is difficult to find a number of evaluations where the interests of a political group are determining to the extent of influencing decisions of the specific intervention under assessment.

\section{Institutional lens}

As seen earlier, RBM emerged at a time of functional pressures in the development aid sector. The sector became widely associated to poor performance and lack of transparency, and awareness of the need for much more focused, efficient and effective development organisations increasingly raised. In particular, UNDP faced strong global pressures to streamline its programmatic activities and gain focus while addressing effectiveness. UNDP even suffered a diminution of its funding during the 1990s, which catalysed reforms towards adopting an effective RBM approach by the end of the decade. Therefore, member States manipulation of funds made UNDP to comply with emerging rules and standards for resultsorientation in the public sector. Since then, RBM has been a managerial priority for UNDP. After succeeding in stabilising its resource base and regaining the confidence of the public, fear of downsizing of its programmatic activities has continued (UNDP, 2007).

In effect, today's fierce competition for funds in the development industry means that securing financing is a major concern to UNDP (and all development organisations, in general). In this setting, the agency remains aware of the need to exceed donor demands for financial accountability and demonstrate focus on performance measurement to increase its chances of survival and flow of resources. Today the development context, saturated with binding expectations for accountability and results, experiences the blossoming of new fates such as MfDR and knowledge aid. Having development, project and program effectiveness and learning becoming a recurring theme in the development discourse, NGO's corporate response has been to adjust its results framework so as to portray an image of consent with the donor's requirements and the wider environment.

Therefore, since the reforms towards RBM started, the organisational tendency in most NGOs has been to adjust the approach according to shifting donor priorities, while seeking routines and universal rules. Major international development organisations (World Bank, USAID, CIDA, Danida, SIDA, etc.) have all adopted the RBM approach and embarked in this course to conform environmental elements deemed legitimate, namely accountability, transparency, focus on results, effectiveness, evaluation, learning and many others.

Presently, it can be argued that the development aid sector is undergoing a process of homogenisation. This process started at small scale and today, many donors have influenced NGOs to implement RBM, especially bearing in mind that most organisations have followed the same path of reform (common mistakes have been made, and same lessons have been drawn). Coghlan (2001) expressed the urgency and the need for NGOs to develop appropriate 
mechanisms for Results-based M \& E to demonstrate their effectiveness. In this regard, the evaluation of such interventions could boost their importance by proving positive results and lobby for continued support from donors. Arguably the understanding of M \& E as a social construct means that the ability of organisations to make their own choices and act independently is not considered in the analysis.

\section{Challenges in the $M$ \& $E$ Results-Based Management}

The desire to achieve results in development cooperation has always been part of the aid agenda, and various methods and approaches have been implemented to achieve this end. During the 1970s and 80s, results management was applied to project aid through methods such as the Logical Framework Approach. NORAD (2008) indicated that a fragmented aid landscape, with donors working on their own projects, did not lead to sustained development results; there was an emerging need for donors to change their methods of thinking and working.

Joint Global goals on what to do and how to achieve the ultimate objective of development cooperation, i.e. poverty reduction, were agreed upon via the Millennium Development Goals and the Paris Declaration on Aid Effectiveness. Results management became an integral part of development. During the 1990s, it transformed from being project-specific to a more organisation and programme-wide level. During the 2000s, a results focus has increasingly moved towards including organisations and systems in partner countries.

\section{Results-based Management is complex to handle at organisational and human level.}

It is repeatedly reported that the results management perspective, in its more holistic form results--based management, is ambitious. One is asking mostly non-results-oriented organisations to institute large measures of change in planning, reporting, and implementation. When introduced at an organisational level, there seems to be a tendency to interpret the results perspective as mechanistic and deterministic, in contrast with analytic and responsive-to-change notions. The review conducted by UNDP (2001) suggested that organisations often fail to make out workable results oriented models, or even put performance information to use as intended by results management.

\section{Different purposes create conflicts in application}

Uncertainty in the development community about what results management means and is used for is likely to stem from a variety of motivations and objectives (Mayne, 2007a). Diversity of objectives includes disbursement levels, accountability (domestic as well as mutual), control, and planning and learning. For donors, there is a conflict in the dual objective of supporting NGOs result management systems while simultaneously improving their own. Hence the representation of "results-oriented practices", in such situations is very ambiguous.

\section{RBM goes against Management practices centred on control and process}

It appears that when the results perspective confronts management practices Centred on control and/or process, managers are inclined to look away from the outcome level, and turn their attention to what is easily measurable (normally indicators found on the levels of input-activity---output). Specifically, it seems that the call for a results focus on "outcomes" has contributed to risk-averse behaviour by donor agencies (Mayne, 2007a). The challenge of introducing "new" Management perspectives also seem to be aggravated in partner countries, where the agenda is at times seen as driven by donors, and with low demand in NGOs.

\section{The systemic and cultural demands put on development partners}

Working with monitoring and evaluation in environments where information is scarce, and national demand for performance information to influence policy and decision--making is weak, presents natural challenges for results orientation and mutual accountability (Poate, 
2012). It is also evident that donors face difficulties in simultaneously strengthening and aligning with development partner systems for planning and performance assessment.

On these grounds, among others, the results agenda has been questioned to the point to suggesting that the entire idea is flawed. It may be that basic notions lead to misuse on a level surpassing any potential benefits, and that it is beyond our reach to increase aid effectiveness. However, that reasoning requires an alternative. From our somewhat limited vantage point, suggested remedies tend to rely on the notions of improved analysis and learning from past experiences.

Today the agenda is being pushed stronger than ever. There is an increased global and domestic demand to demonstrate the results of development cooperation. The effects of traditional forms of development cooperation are being questioned publicly. New modalities and actors are entering the scene and thus, the complexity, number of actors, and ways of doing business, has never been greater. Results requirements are increasingly being used as a condition for funding: "without-results no funding and no collaboration" (NORAD, 2013c).

\section{Research Methodology}

\section{Introduction}

This section present the methods of investigation the researcher used. It is composed of research design, sample size and sampling procedure, sources of data, tools of data collection and data analysis as well as limitations. Research methodology refers to way of systematically solving the research problem or a science of studying how the research is done scientifically (Kothari, 2004).Therefore, in this research study both qualitative and quantitative methods were used to triangulate the data gathering. Qualitative methods are based on the facts which are socially constructed and peoples experience with regards to an issue under study (Best, 1963).

\section{Research Design}

"A research design is the arrangement of conditions for collection and analysis of data in a manner that aims to combine relevance to the research purpose with economy in procedure" (Barley, 1978. In other words, research design is structure, plan, blue print, logical model that enable a researcher to come up with the solutions or answers to the research problem or question.

Research design also show clearly where the data will be collected, procedures and techniques to be used for gathering information or the methods of data collection to be used, processing and analysing data, skills of the researchers and the availability of staff, money and also the amount of time required to conduct the research study (Allen, 1978). In this research study a non-experimental research design in the form of descriptive study was used to present the facts on the ground. Additionally, the research used statistical tools to evaluate the accuracy of the data to present information.

\section{Sources of Data}

Data used were from both primary and secondary sources.

\section{Primary Data}

Primary data were gathered by administering structured questionnaires. This primary data were both quantitative and qualitative. The quantitative data was used to give statistics of the study. Furthermore, to enrich the quantitative data (statistics), the qualitative data was gathered using the same questionnaire which had both closed and open-ended questions. Primary data are important for this study because they come directly from the people on the ground. 
South American Journal of Management

Special Edition 2016

\section{Secondary Data}

Secondary data collection involved literature review of the research findings of previous studies and other published documents such as articles, journals, and books relating to the research topic as well as the internetas shown in chapter two of the literature review. Secondary data was important for this study to show other researchers have done in similar topic in other countries and compare their findings with the findings of this research study. Secondary data are also important because they help to identify gaps in previous studies.

\section{Target Population}

The target NGOCC Member Organisations of the study was one hundred and four (104). The NGOCC Membership is spread across the country in all ten provinces, and it from this membership a sample size was drawn from.

\section{Sample Size}

The sample size included respondents from NGOCC Member Organisations. About 25 organisations were selected from seven provinces. Note that during the interviews organisations were being represented as follows: 11 organisations (44 percent) had 1-3 representatives, 6 organisations ( 24 percent) had 4-6 representatives, while 8 organisations (32 percent) had 7 and above representatives. Reasons for choosing this sample size include cost effectiveness, manageability and adequacy in generation of precise data.

\section{Sampling Method}

The process of selecting part of or sub-set of the population (sample size) is called sampling. Sampling could be either probability or non-probability (Cochran, 1963). In this research study probability sampling technique to select the sample for the study was used. One variant of cluster sampling, that is, systematic sampling was used to select NGOCC Member Organisations.

NGOCC has detailed list of all Member Organisations and all the organisations were assigned a sampling number, hence the organisations were selected following this procedure:-

1. Calculate the sampling interval $\mathrm{I}=\mathrm{N} / \mathrm{n} \quad 104 / 25=4.16$ which is 4 when rounded off.

- Where "N" is the total number of NGOCC Member Organisations was 104.

- Where " $n$ " is the number of sample size (25) wanted and Sampling Interval is 4.

2. Generating random number $(\mathrm{R})$ between 1 and interval, the first selection will be $\mathrm{R}$ (4).

3. The starting point will be randomly chosen.

4. To get to the next selection addition of the interval 4 will be done

5. Adding the interval repeatedly until the desired sample size was reached.

During the research, selected organisations who were not at available during the monitoring visit of the projects on the appointed data replacement was done using a sampling interval to select another organisations until the required sample size was reached.

\section{Research Instruments}

\section{Questionnaires}

Structured questionnaires were used to collect data from respondents. The research tools comprised of closed-ended questions with predetermined answers, while open- ended questions required the respondents to write their own responses. These questionnaires were developed and distributed to the respondents by the researcher. Questions were aimed at eliciting relevant information from the respondents.

\section{Pre-Testing of the Research Instruments}

The pilot study was conducted by administering the questionnaires to the similar group of respondents (with similar characteristics) of study in Lusaka. Two NGOCC member 
organisations such as Women for Change and World of Prayer participated in pre-test of tools. The questionnaires were administered to the respondents inform of interview. The research questionnaires were pre-tested to enhance validity of the content, some questions were modified and new questions were in the questionnaires, improve on questions and the format of the research tools.

\section{Data Analysis}

\section{Editing}

Data cleaning was done after data entry to minimize errors by checking on completeness, accuracy and uniformity. Errors were corrected and responses put in the right place.

\section{Coding}

After the data was collected, the questions and responses were coded to ensure that all values and variables under study were correctly defined and captured in the data set. The coding of the responses helped to group similar responses to the questions into meaningful categories. The data collected from the questionnaire were checked for uniformity, consistency and accuracy.

The responses were coded for easy data analysis. Analysis and interpretation of data was done with the help of computer software and statistical tools such as Microsoft Excel (Msexcel) and Statistical Package for Social Science (SPSS). Data entry was done using Ms-excel and exported to SPSS version 16.0. The advantage of SPSS is that it is user friendly, it has enough space for a long range of numbers and mathematical manipulations can be dealt with using its in-built functions. To aid the interpretation of data; pie and bar charts, tables and percentages were used. On the other hand qualitative data were analysed manually by creating themes based on the responses given by the respondents.

\section{Ethical Considerations}

Ethics in social science research should be observed when undertaking research study. To reduce psychological and emotional harm of the respondents, ethical consideration was of great importance. Ethics in this research study were highly considered by the researcher by seeking informed consent from the participants and disclose the aims of the research. Voluntarism was also considered as participants were not forced or coerced to participate in the study. Confidentiality was also considered to protect respondents from any psychological or physical harm and danger against their participation in the study and the identity details of the participants were kept confidential. The data collected from respondents were kept in a secure and private place.

\section{Data Analysis and Results Presentation \\ Introduction}

This chapter presents the research findings of the study. It also presents questions in diagrammatical form especially those which related to the research objectives to give evidence-based statistics. The same findings were used for discussion to explain what they entail and also to compare with what other researchers had written.

\section{Responses to the Questions}

\section{Organisation}

In this research study about 25 NGOCC Member Organisations which include NonGovernmental Organisations (NGOs) and Community Based Organisations (CBOs) participated. These include Breastfeeding Association of Zambia (BAZ), Senior Citizens Association of Zambia (SCAZ), Society for Women and AIDS in Zambia (SWAAZ), Zambia National Womens' Lobby (ZNWL), Zambia Women Development Association (ZAWEDA), Zambian Women in Mining, Community for Human Development (CHD), Council of 
South American Journal of Management

Special Edition 2016

Churches in Zambia (CCZ), Kalomo District Women Association, Law Development Association (LADA), Maliko Area Association, Monze District Women's Association, Kambwize Area Assoication, Mangango Area Association, Mufaya Area Association, Likunde Area Assoication, Liye-Liye Area Association, People's Participation Service (PPS), Zambia Orphans Widows Assoication (ZOWA), Mabumba Nutrition Group, Mansa District Women's Association, Single Parents Association of Zambia (SPAZ), Development of People's Empowerment (DOPE), Mwelebi Kembe Ranch Home Based Care (MKAMBECO), and Twikatane Area Association.

Table 4.1: Number of Organisation per Province

\begin{tabular}{|ll|l|l|}
\hline RESPONSES & & FREQUENCY & PERCENT \\
\hline Valid & Lusaka & 8 & 32.0 \\
& Western & 6 & 24.0 \\
& Central & 1 & 4.0 \\
& Luapula & 3 & 12.0 \\
& Southern & 4 & 16.0 \\
& Muchinga & 2 & 8.0 \\
& Copperbelt & 1 & 4.0 \\
& Total & $\mathbf{2 5}$ & $\mathbf{1 0 0 . 0}$ \\
\hline
\end{tabular}

In table 4.1 above, it shows that a number of organisations that participated in the research study were from Lusaka Province which had eight (8) representing 32 percent, followed by Western Province which had six (6) representing 24 percent. The other four (4) organisations representing 16 percent were from Southern Province, while Copperbelt and Central Provinces only one organisation representing 4 percent in each participated in the research study.

Table 4.2: Organisation representatives during interview

\begin{tabular}{|ll|l|l|}
\hline RESPONSES & & FREQUENCY & PERCENT \\
\hline Valid & $1-3$ & 11 & 44.0 \\
& $4-6$ & 6 & 24.0 \\
& 7 \& above & 8 & 32.0 \\
& Total & $\mathbf{2 5}$ & $\mathbf{1 0 0 . 0}$ \\
\hline
\end{tabular}

Table 4.2 above shows the representation of the organisations during the interviews. The statistics show that 11 organisations (44 percent) had 1-3 representatives, 6 organisations (24 percent) had 4-6 representatives, while 8 organisations (32 percent) had 7 and above representatives. These statistics means that the organisations were well represented during the interviews, and that the information given on Monitoring and Evaluation systems and or Results Based Management reflected some actual situation of the organisation because it was not given by only person from the organisation. It should be pointed out that the minimum number of the organisation representatives interviewed were three.

Table 4.3: Number of donors apart from NGOCC

\begin{tabular}{|ll|l|l|}
\hline RESPONSES & & FREQUENCY & PERCENT \\
\hline Valid & 0-3 donors & 22 & 88.0 \\
& 4-6 donors & 2 & 8.0 \\
& 7 \& above donors & 1 & 4.0 \\
& Total & $\mathbf{2 5}$ & $\mathbf{1 0 0 . 0}$ \\
\hline
\end{tabular}

Table 4.3 above shows the number of donors from which the organisations get funding apart from NGOCC. The findings have revealed that 22 (88 percent) organisations have $0-3$ donors who provide funding, 2 (8 percent) organisations have 4-6 donors who provide funding, whilst 1 (4 percent) organisation has above 7 donors who provide funding apart from 
NGOCC. Evidently the statistics show that most organisations have few donors from which they receive funding, and in most cases it was noted that many organisations have no other donors apart from NGOCC. It can also be attested that more than three-quarters of NGOCC Member Organisations if not all, depend on NGOCC for funding, hence dependency syndrome is higher.

Table 4.4: Introduction of $M \& E /$ Result Based Management to Organisation in programs

\begin{tabular}{|ll|l|l|}
\hline RESPONSES & & FREQUENCY & PERCENT \\
\hline Valid & Yes & 14 & 56.0 \\
& Somehow & 10 & 40.0 \\
& Do not know & 1 & 4.0 \\
& Total & $\mathbf{2 5}$ & $\mathbf{1 0 0 . 0}$ \\
\hline
\end{tabular}

Table 4.4 shows number of organisations that have been introduced to M \& E/Result Based Management in project/program. The above findings have shown that 14 (56 percent) organisations have been introduced to $\mathrm{M} \& \mathrm{E} /$ Result Based Management in project/program, 10 (40 percent) organisations have somehow been introduced, and the other one (4 percent) organisation does not know whether the organisation was introduced to $M$ \& E/Result Based Management in project/program.

Table 4.5: The introduction of $M$ \& E/Result Based Management

\begin{tabular}{|ll|l|l|}
\hline RESPONSES & & FREQUENCY & PERCENT \\
\hline Valid & Donors/funders & 22 & 88.0 \\
& Network organisations & 2 & 8.0 \\
Missing & Total & 24 & 96.0 \\
Total & not applicable & 1 & 4.0 \\
& & $\mathbf{2 5}$ & $\mathbf{1 0 0 . 0}$ \\
\hline
\end{tabular}

Furthermore, the research findings revealed that 22 organisations ( 88 percent) indicated that they were introduced to $\mathrm{M} \& \mathrm{E} / \mathrm{Result}$ Based Management in project/program by donors, while only 2 ( 8 percent) organisations were introduced by network organisations as shown in table 4.5 above. Therefore, it can be attested that donors are more interested and have influenced the introduction of $\mathrm{M} \& \mathrm{E} /$ Result Based Management in project/program compared to the network organisations.

Table 4.6: The explanation on the importance of $M \& E$ E/Result Based Management

\begin{tabular}{|ll|l|l|}
\hline & RESPONSES & FREQUENCY & PERCENT \\
\hline Valid & Greater extent & 12 & 48.0 \\
& Less extent & 12 & 48.0 \\
& Total & 24 & 96.0 \\
Missing & not applicable & 1 & 4.0 \\
Total & & $\mathbf{2 5}$ & $\mathbf{1 0 0 . 0}$ \\
\hline
\end{tabular}

The above table 4.6 shows the extent to which the donors and or other stakeholders and network organisations explain the importance of $M \& E /$ Result Based Management in the program. The findings have revealed that 12 (48 percent) organisations indicated that the explanation on the importance of $M$ \& E/Result Based Management in the program was greater, whilst the other 12 (48 percent) organisations indicated that the explanation was less.

Table 4.7: Importance of M \& E/Result Based Management in project/program

\begin{tabular}{|l|l|l|l|l|}
\hline QUESTIONS & \multicolumn{3}{|l|}{ RESPONSES } & \\
\cline { 2 - 5 } & YES & NO & $\begin{array}{l}\text { DO } \\
\text { NOT }\end{array}$ & Total \\
\hline
\end{tabular}


South American Journal of Management

Special Edition 2016

\begin{tabular}{|l|l|l|l|l|}
\hline & & & KNOW & \\
\hline $\begin{array}{l}\text { Does M \& E enhance project management } \\
\text { decision making during the implementation? }\end{array}$ & $24(96 \%)$ & $0(0 \%)$ & $1(4 \%)$ & $100 \%$ \\
\hline $\begin{array}{l}\text { Does M \& E ensure that implementation of } \\
\text { program is according to plans? }\end{array}$ & $24(96 \%)$ & $0(0 \%)$ & $1(4 \%)$ & $100 \%$ \\
\hline $\begin{array}{l}\text { Does M \& E enhance transparency and } \\
\text { accountability of resources to the donors and } \\
\text { other stakeholders? }\end{array}$ & $23(92 \%)$ & $0(0 \%)$ & $2(8 \%)$ & $100 \%$ \\
\hline $\begin{array}{l}\text { Does M \& E enhance the performance in } \\
\text { results-based reporting (outputs, outcomes } \\
\text { and impacts)? }\end{array}$ & $24(96 \%)$ & $0(0 \%)$ & $1(4 \%)$ & $100 \%$ \\
\hline $\begin{array}{l}\text { Do M \& E systems act as the Resource } \\
\text { Mobilisation tools for the organisation? }\end{array}$ & $24(96 \%)$ & $0(0 \%)$ & $1(4 \%)$ & $100 \%$ \\
\hline
\end{tabular}

Although 12 (48 percent) organisations indicated that the explanation on the importance of $M \&$ E/Result Based Management in the program was less, the statistics in Table 4.7 have clearly shown that $M \& E$ enhances decision making; ensures implementation of program according to plans; enhances transparency and accountability of resources to the donors and other stakeholders; enhances performance in results-based reporting; and also act as the Resource Mobilisation tools for the organisation being represented by 24 (96\%), 24 (96\%), 23 (92\%), 24 (96\%), and 24 (96\%) respectively.

\section{Organisation adaptation to the introduction of $M$ \& $E$ /Result Based Management systems}

On the adaptation to the introduction of M \& E / Result Based Management systems by the organisations, the research findings have revealed that those organisations which have established and operational M \& E /Result Based Management systems with M \& E Officer and or office have adapted very well. Furthermore, organisations which somehow have basic M \& E /Result Based Management systems in place such as M \& E Officer volunteers as well as the use of existing staff and guidance have also tried to adapt to the new reporting processes. On the other hand, the organisations which do not have basic M \& E /Result Based Management systems in place have not directly adapted due to inadequate staff, lack of understanding and knowledge in $\mathrm{M} \& \mathrm{E}$, and also low levels of education among members.

\section{User -friendly of M \& E/Result Based Management systems introduced}

Taking into of varying organisation levels, the representatives from the organisations were asked how friendly the M \& E/Results based management systems introduced. Three-quarters of the organisations which participated in this study indicated that the newly introduced reporting format was user friendly. The other one-quarter of the organisations which participated in this study indicated that the newly introduced reporting format was user friendly, however staff face challenges to follow the format and even to fill the data capturing tools correctly due to low levels of education among organisation members who are actually running the day today affairs (operations) of the organisation. Therefore, it was recommended that donors should provide much needed guidance on tailor made basis taking into account of the organisation needs, and the level at which the organisation is.

Table 4.8: Basic $M \& E$ /Result Based Management systems in place

\begin{tabular}{|ll|l|l|}
\hline RESPONSES & & FREQUENCY & PERCENT \\
\hline Valid & Yes & 11 & 44.0 \\
& Somehow & 10 & 40.0 \\
& No & 4 & 16.0 \\
& Total & $\mathbf{2 5}$ & $\mathbf{1 0 0 . 0}$ \\
\hline
\end{tabular}


Table 4.8 shows that 11 (44 percent) organisations have an established and operational M \& E /Result Based Management systems such as M \& E Officer and or office, objectives of the projects, indicators, data capturing tools and databases. The 10 (40 percent) organisations somehow have basic M \& E /Result Based Management systems in place such as objectives of the projects, and data capturing tools only, while 4 (16 percent) organisations do not have basic M \& E /Result Based Management systems in place.

\section{Organisation challenges for not having basic M \& E /Result Based Management systems}

The study was also aimed at investigating the challenges which organisations face for not having basic M \& E /Result Based Management systems. The findings of this research study revealed the major challenges as being inadequate financial resources to employ Monitoring and Evaluation Officer who can be fully in charge of putting in place such basic M \& E processes. Worse still most organisations are CBOs whose members are of low education levels to assimilate and have a clear understanding of such basic $\mathrm{M} \& \mathrm{E}$ processes. Although organisations appreciate the importance of $M \& E$ processes, low education levels among organisation members running the organisations or office bearers has remain a challenge to operationalise such processes.

Table 4.9: Monitoring and Evaluation Officer for the organisation

\begin{tabular}{|ll|l|l|}
\hline & RESPONSES & FREQUENCY & PERCENT \\
\hline Valid & Yes & 2 & 8.0 \\
& Somehow & 5 & 20.0 \\
& No & 18 & 72.0 \\
& Total & $\mathbf{2 5}$ & $\mathbf{1 0 0 . 0}$ \\
\hline
\end{tabular}

During the interviews the representatives from the organisations were asked whether they have Monitoring and Evaluation Officer. Table 4.9 above shows that only 2 (8 percent) organisations have Monitoring and Evaluation Officers in place that carry out M \& E functions. 5 (20 percent) organisations indicated that they have somehow Monitoring and Evaluation Officers in place. The organisations that indicated of having Monitoring and Evaluation Officers somehow, in actual sense they meant that Project Officers, and other existing staff were also carrying out $\mathrm{M} \& \mathrm{E}$ functions in directly and or indirectly. On the other hand 18 (72 percent) organisations do not have either Monitoring and Evaluation Officer or existing staff to and carrying out $\mathrm{M} \& \mathrm{E}$ functions. It is important to note that the reason for not having Monitoring and Evaluation Officer in place was mainly due to inadequate financial resources. However, one organisation indicated that plans were underway to recruit the $\mathrm{M} \& \mathrm{E}$ Officer.

Table 4.10: Quality and content of the reports in terms of results/successes

\begin{tabular}{|ll|l|l|}
\hline & RESPONSES & FREQUENCY & PERCENT \\
\hline Valid & Very good & 5 & 20.0 \\
& & & 56.0 \\
& Good & 14 & 24.0 \\
& Average & 6 & $\mathbf{1 0 0 . 0}$ \\
\hline & Total & $\mathbf{2 5}$ & \\
\hline
\end{tabular}

The respondents were asked to rate their organisation reports in terms of quality and content. It was revealed that 5 (20 percent) organisations their project reports are very good, $14(56 \%)$ organisations their project reports are good, while 6 (24 percent) organisations rated their reports to be on average as shown in Table 4.10 above.

Table 4.11: Support to strengthen M \& E /Result Based Management systems

\begin{tabular}{|l|l|l|}
\hline RESPONSES & FREQUENCY & PERCENT \\
\hline
\end{tabular}


South American Journal of Management

Special Edition 2016

\begin{tabular}{|ll|l|l|}
\hline Valid & Yes & 15 & 60.0 \\
& Somehow & 10 & 40.0 \\
& Total & $\mathbf{2 5}$ & $\mathbf{1 0 0 . 0}$ \\
\hline
\end{tabular}

It is evident that organisations were provided with support to strengthen the $\mathrm{M} \& \mathrm{E} /$ Result Based Management systems. 15 (60 percent) organisations were provided with support, while 10 (40 percent) organisations were somehow provided with support to strengthen the M \& E /Result Based Management systems as shown in Table 4.11 above.

Table 4.12: Support provided to the organisations by donors and or network organisations

\begin{tabular}{|ll|l|l|}
\hline RESPONSES & FREQUENCY & PERCENT \\
\hline Valid & $\begin{array}{l}\text { Capacity building in M \& E/RBM systems, } \\
\text { reporting and Financial support and } \\
\text { management through orientation }\end{array}$ & 24 & 96.0 \\
$\begin{array}{l}\text { Governance and project management } \\
\text { Total }\end{array}$ & 1 & 4.0 \\
\hline
\end{tabular}

Table 4.12 shows the support the donors and or network organisations have provided to organisations to strengthen the M \& E /Result Based Management systems. As evident above, the findings have revealed that 24 (96 percent) organisations were supported to strengthen the $\mathrm{M} \& \mathrm{E} /$ Result Based Management systems through orientation in M \& E/RBM systems, reporting and financial management. Interestingly, 1 (4 percent) organisation was supported in governance problem resolutions through guidance in constitution development process and bringing the organisational members together to resolve the differences, and also the project management through orientation.

\section{Adequacy of support to meet the needs of the organisation}

In relation to support provided by the donors to organisations through orientation in $M \&$ E/RBM systems, reporting and financial management, one quarter (1/4) of the organisations which participated in this research study indicated that the support (orientation) was adequate and it has helped the organisation in the reporting processes. Furthermore, other organisations were provided with financial support project officers and M \& E Officers were employed to plan and implement, and to monitor and evaluate the projects respectively. However it is important to note that three-quarters of the organisations indicated that support provided was not adequate. The reasons among other included weak organisation capacity which mainly attributed to inadequate human resources, low education levels among organisation members, and lack of tailor made orientation in the $\mathrm{M} \& \mathrm{E}$ processes and it was one off considering varying education levels especially members in Community Based Organisations (CBOs).

\section{Discussion of the Research Findings}

To investigate the extent to which the donors have explained to NGOs the importance of results-based management and the support which donors provide to NGOs to strengthen results-based management:-

The first research objective was to investigate the extent to which the donors have explained to NGOs the importance of results-based management. In relation to this objective, the findings revealed that 12 (48 percent) organisations indicated that the explanation on the importance of $\mathrm{M} \& \mathrm{E} /$ Result Based Management in the program was greater, whilst the other 12 (48 percent) organisations indicated that the explanation was less. These findings entail that donors explanation on the importance of results-based management to NGOs is almost $50 \%$ greater and $50 \%$ less. Arguably the donors are encouraged to scale up the efforts to explain the importance of results-based management to other Member organisations.

It should be stated that, comprehensive and clear explanation on the importance of doing something to an individual or organisation, is the first step to change the attitude or perception 
thereby bringing the spirit of willingness to do it for the benefits stated or explained. It is imperative for the donors to include the explanation of the result chain which follows as inputs (human resources, computers, finances, etc); processes (activities which have planned in the project and or program); outputs (immediate results achieved due to the implementation of the planned activities); outcomes (which are short-term or intermediate results at population level the execution of the planned activities); and the impact (which ate long-term effects, or the end results of the program) as outline by Kusek, J.Z. and Rist, R. C. (2004).

Therefore, donors and or other stakeholders and network organisations should continue or intensify the provision of comprehensive and clear explanation on the importance of $\mathrm{M} \&$ $\mathrm{E} /$ Result Based Management in the program so that partner organisations can appreciate and be committed to this new process of results-based reporting. However, there is need to take into account of the organisation capacities which maybe at varying levels to adapt to resultsbased approaches.

Furthermore the first objective endeavours to investigate the support which donors provide to NGOs to strengthen results-based management. The findings have shown that organisations were provided with support to strengthen the $\mathrm{M} \& \mathrm{E} /$ Result Based Management systems. Notably 15 (60 percent) organisations were provided with support, while 10 (40 percent) organisations were somehow provided with support to strengthen the M \& E /Result Based Management systems as shown in Table 4.11 above.

Additionally the findings have revealed that 24 (96 percent) organisations were supported to strengthen the $\mathrm{M} \& \mathrm{E} /$ Result Based Management systems through orientation in $\mathrm{M}$ \& E/RBM systems, reporting and financial management by the donors. Interestingly, 1 (4 percent) organisation was supported in governance problem resolutions through guidance in constitution development process and bringing the organisational members together to resolve the differences, and also the project management through orientation.

Furthermore, the support provided by the donors to organisations in M \& E/RBM systems, reporting and financial management, one quarter (1/4) of the organisations which participated in this research study indicated that the support (orientation) was adequate and it has helped the organisation in the reporting processes. Additionally other organisations were provided with financial support which they use to employ the project officers and M \& E Officers to plan and implement, and to monitor and evaluate the projects respectively.

However it is important to note that three-quarters of the organisations indicated that support provided was not adequate. The reasons among other included weak organisation capacity which mainly attributed to inadequate human resources, low education levels among organisation members, and lack of tailor made orientation in the M \& E processes and it was one off considering varying education levels especially members in Community Based Organisations (CBOs). The inadequacy of support entails that most of the organisations especially CBOs may face a numerous challenges to adapt to Results-Based approaches due to organisational inadequate capacities.

Based on these research findings, there is need for donors/funders to increase the budget allocation to $\mathrm{M} \& \mathrm{E}$ activities, provide adequate data capturing tools, and also to providing tailor made orientations and trainings in the $\mathrm{M} \& \mathrm{E}$ processes considering the fact that organisations are at varying levels and also capacities. This would help to strengthen the M \& E processes in the organisations being supported.

\section{To determine the extent to which NGOs understand the importance of results-based management in their programs:}

The second research objective was to determine the extent to which NGOs understand the importance of results-based management in their programs. The research findings have revealed that the donors, network organisations explain the importance of $M$ \& $E /$ Result Based Management in the program. The 12 (48 percent) organisations indicated that the explanation on the importance of $M$ \& E/Result Based Management in the program was greater, whilst the other 12 (48 percent) organisations indicated that the explanation was less. 
South American Journal of Management

Special Edition 2016

It should be argued that though, the research findings revealed that almost half of the organisations 12 (48 percent) indicated that the explanation on the importance of $\mathrm{M} \&$ $\mathrm{E} /$ Result Based Management in the program was less, the statistics have clearly shown that $\mathrm{M}$ $\&$ E enhances decision making; ensures implementation of program according to plans; enhances transparency and accountability of resources to the donors and other stakeholders; enhances performance in results-based reporting; and also act as the Resource Mobilisation tools for the organisation being represented by 24 (96\%), 24 (96\%), 23 (92\%), 24 (96\%), and $24(96 \%)$ respectively.

These findings are being supported by some of findings in the literature review. The literature revealed that results-based $\mathrm{M} \& \mathrm{E}$ should be integrated into the programme/project cycle because they offer informed judgements upon the organisation performance as well as guiding staff's decision making and interventions. However, it is important to note that the impact of Results-based $M \& E$ on decision-making is questionable. Presently, there is no sound evidence that information upon results is used in a systematic way to inform adjustments on interventions and operations during the project and/or implementations (UNDP, 2007). It is argued that the mostly the information structures are placed or centralised at $\mathrm{M} \& \mathrm{E}$ centres and or offices; hence to produce appropriate knowledge systematically for managerial purposes has remained a major problem. Evidently there is also a persistent lack of good and critical data because it has been mostly the organisations report mainly on the inputs and the delivery of outputs and not on outcomes as demanded by most donors.

Furthermore, it has been noted that the available data do not only lacks quality, but also fails to provide impartial answers to the results achieved because of interventions. In short the attribution of the results achieved to the organisations efforts and the interventions or implemented activities have continued to be a challenge for most of the organisations. Additionally, it has been observed that the formulation of indicators is contaminated including those indicators which are carefully chosen to measure results in the best possible light. The credibility of measurement and assurance of quality data in most international organisations and local organisation is therefore at stake. Herein, the monitoring of progress of the projects and/or programs does not prove convincing because of managers' subjectivity and lack of good data.

It should be stated that multi-layered accountability framework indicates that different groups have different interests with regards to evaluative evidence and information. The accountability framework for results has been therefore premised on a hierarchy of three pillars, namely organisational, programmatic and staff accountability (Berg, 2007). In this respect, the NGOs have been pursuing a corporate agenda of meeting demands from donors for reporting and better financial administration especially at organisational level.

In general, RBM procedures have been centrally-driven and prioritise corporate requirements such as demonstrating accountability and financial soundness. At the programmatic level, the donors' interests for reporting and accountability are of paramount. Meeting reporting commitments is paramount and has become more important than learning to better manage the results. Notably, due to poor performance and lack of transparency, and awareness of the need for much more focused, efficient and effective the introduction of $\mathrm{RBM}$ is in the organisations has been deemed necessary even in the international organisations.

In particular, for instance UNDP faced strong global pressures to streamline its programmatic activities and gain focus while addressing effectiveness. UNDP suffered from inadequate financial funding during the 1990s, which catalysed reforms towards adopting an effective RBM approach by the end of the decade. The country member states attached conditionalities to the funding which made UNDP to comply with emerging rules and standards for results-orientation in the program management. Since then, RBM has been a managerial priority for UNDP. The adoption of the R B approach by the UNDP helped it to succeed in stabilising its resource base and regaining the confidence of the public in its programmatic activities (UNDP, 2007). 
It is therefore important to state that organisations should be aware of the need to exceed donor demands for financial accountability and demonstrate focus on performance measurement to increase its chances of survival and flow of resources. Currently, the funding is saturated with binding expectations for accountability and results; hence development project and program effectiveness and learning becoming a recurring theme in the development discourse. In 2001 (Coghlan), expressed the urgency and the need for NGOs to develop appropriate mechanisms for Results-based M \& E to demonstrate their effectiveness. In this regard, the evaluation of such interventions could boost their importance by proving positive results and lobby for continued support from donors. Arguably the understanding of $\mathrm{M} \& \mathrm{E}$ as a social construct means that the ability of organisations to make their own choices and act independently is not considered in the analysis.

From the above, it can be argued that, although there are weaknesses and problems in the $\mathrm{M} \& \mathrm{E}$ processes as noted above, there is a need for comprehensive and clear explanation on the importance of doing something to an individual or organisation, is the first step to change the attitude or perception thereby bringing the spirit of willingness to do it for the benefits stated or explained. Therefore, donors and or other stakeholders and network organisations should continue to provide comprehensive and clear explanation on the importance of $\mathrm{M} \&$ $\mathrm{E} /$ Result Based Management in the program so that partner organisations can appreciate and be committed to this new process of results-based reporting.

\section{To identify the challenges faced by NGOs in the results-based management and interventions/recommendations to donors and NGOs to help them improve their results- based management.}

The third research objective was to identify the challenges faced by NGOs in the resultsbased management and interventions/recommendations to donors and NGOs to help them improve their results-based management. The findings of this research study revealed the major challenges as being inadequate financial resources to employ Monitoring and Evaluation Officer who can be fully in charge of putting in place such basic M \& E processes. Worse still most organisations are $\mathrm{CBOs}$ whose members are of low education levels to assimilate and have a clear understanding of such basic $\mathrm{M} \& \mathrm{E}$ processes.

Additionally, it is evident that 11 (44 percent) organisations have an established and operational M \& E /Result Based Management systems such as objectives of the projects, indicators, data capturing tools and databases. On the other hand 10 (40 percent) organisations somehow have basic M \& E /Result Based Management systems in place such as objectives of the projects, and data capturing tools only, and 4 (16 percent) organisations do not have basic M \& E /Result Based Management systems in place. It was furthermore revealed that 2 (8 percent) organisations have Monitoring and Evaluation Officers in place that carry out $\mathrm{M}$ $\&$ E functions. Evidently 5 (20 percent) organisations indicated that they have somehow Monitoring and Evaluation Officers in place.

The organisations that indicated of having Monitoring and Evaluation Officers somehow, in actual sense they meant that Project Officers, and other existing staff were also carrying out $\mathrm{M} \& \mathrm{E}$ functions in directly and or indirectly. On the other hand 18 (72 percent) organisations do not have either Monitoring and Evaluation Officer or existing staff to and carrying out $\mathrm{M}$ \& $\mathrm{E}$ functions. It is important to note that the reason for not having Monitoring and Evaluation Officer in place was mainly due to inadequate financial resources. However, one organisation indicated that plans were underway to recruit the $M \&$ E Officer. It should be noted that although organisations appreciate the importance of $\mathrm{M} \& \mathrm{E}$ processes, low education levels among organisation members running the organisations or office bearers has remain a challenge to operationalise such processes.

Apart from the above challenges, literature review revealed that the introduction of RBM at an organisational level has a tendency to interpret the results perspective as mechanistic and deterministic, in contrast with analytic and responsive-to-change notions. The review conducted by UNDP (2001) revealed that organisations often fail to make out workable 
results oriented models, or even put performance information to use as intended by results management because of inadequate human resources. Furthermore, uncertainty in the development community about what results management means and is used for come about because of different motivations and objectives (Mayne, 2007a). Diversity of objectives includes disbursement levels, accountability (domestic as well as mutual), control, and planning and learning.

It has been noted that for donors, there is a conflict in the dual objective of supporting NGOs result management systems while simultaneously improving their own. Hence the "results-based practices", in such situations is very ambiguous. Although RBM is associated with various as discussed above, the result based agenda is being pushed stronger than ever, and there is an increased global and domestic demand to demonstrate the results of development cooperation. New modalities and actors are entering the scene and thus, the complexity, number of actors, and ways of doing business, has never been greater. Results requirements are increasingly being used as a condition for funding: "without-results no funding and no collaboration" (NORAD, 2013c).

Recommendations to donors strengthen the M \& E /Result Based Management systems.

The third research objective also aimed at seeking interventions and or recommendations to donors and NGOs to help them improve their results-based management. During the interviews, the representatives of the organisations were asked to provide recommendations which could be used to strengthen the M \& E /Result Based Management systems and make the $\mathrm{M} \& \mathrm{E}$ processes a reality. Interestingly the findings revealed that donors should provide tailor made orientation and trainings in $\mathrm{M} \& \mathrm{E}$ and report writing as well as technical support and guidance. It was further recommended that donors should increase budget allocation to $\mathrm{M}$ $\& \mathrm{E}$ activities and also to employ the $\mathrm{M} \& \mathrm{E}$ Officer for project period. The sharing of the data capturing tools to meet the reporting requirements was one of the recommendations which came out strongly from the organisations to the donors.

\section{Measures to strengthen M \& E /Result Based Management systems at organisation level}

During the interviews, the representatives of the organisations were asked to provide or state the measures at the organisation level which could be used to strengthen the $\mathrm{M} \& \mathrm{E}$ /Result Based Management systems and to make the $M$ \& $E$ processes more effective. Generally there was common understanding that there is need to improve and strengthen the data collection process through the use of data capturing tools shared by the donors, and to establish the filing system and documentation of data, success stories and other important information collected from the project sites. It was pointed out strongly that organisation staff or members that attend the orientation and trainings in $\mathrm{M} \& \mathrm{E}$, report writing, financial and project management and other related trainings should orient other staff or members that did not attend the trainings or orientations. The rationale for such idea or measure is to create organisation memory not the knowledge to remain with one staff who in case when he or she leaves the organisation a gap is created thereby negatively affecting the operation of the organisation.

\section{Summary, Conclusion and Recommendations}

\section{Introduction}

Chapter five presents the research summary, conclusion and recommendations based on the research findings. It has also presented areas for further studies.

\section{Research Summary}

The donors have introduced the results-based management (RBM) to improve the effectiveness, efficiency and accountability in the management, operations and implementation of programmes by NGOs. To the donors the introduction of results-based management is one way of promoting efficiency, effectiveness and is one of the 
conditionality's for funding. However results-based management practices among NGOs are generally believed to be ineffective due to the adoption of the wrong RBM strategies, particularly when inappropriately copied from other organisations and start being operationalised without taking into account of the existing knowledge level and skills among the existing staff (Britten 1998). It is not clear whether the importance of results-based management approach has been clearly explained to NGOs so that they can strive harder to incorporate them into programs at the inception.

Furthermore, it is not clear about the challenges which NGOs face to implement the results-based management approach, and the support which donors provide to NGOs for them to effectively implement the results-based management approach is not known. All the factors discussed above have prompted the need to undertake this research study. Given the problem, the main objective was to investigate the importance of the Result Based Management (RBM) in the Project Management and the Challenges Non-Governmental Organisations (NGOs) face to strengthen the RBM system. The specific objectives of study were:-

- To investigate the extent to which the donors have explained to NGOs the importance of results-based management and the support which donors provide to NGOs to strengthen results-based management;

- To determine the extent to which NGOs understand the importance of results-based management in their programs;

- To identify the challenges faced by NGOs in the results-based management and interventions/recommendations to donors and NGOs to help them improve their results-based management.

To achieve the three research objectives, the study was undertaken in seven provinces of Zambia covering twenty-five (25) NGOCC Member Organisations. During the study relevant literature on the on the importance of RBM, and challenges which NGOs face to adapt to RBM processes was reviewed. From the literature review it can be argued that, although $M$ \& E processes have some weaknesses and problems such as persistent lack of good and critical data, M \& E enhances decision making; ensures implementation of program according to plans; enhances transparency and accountability of resources to the donors and other stakeholders; enhances performance in results-based reporting; and also act as the resource mobilisation tools for the organisation

To undertake this research study a clear research methodology was proposed and outlined. Research design, study population, sample size, sampling design, and types of data, research instruments, and data collection method were considered and outlined. Furthermore, data analysis and ethical consideration during the study were also covered. The clearly outlined methodology, helped to carry out this research systematically. The data analysis was done in relation research objectives.

Under the first objective, it can be concluded that there is need for donors, network organisations and stakeholders to continue or intensify the provision of comprehensive and clear explanation on the importance of $M \&$ E/Result Based Management in the program. A comprehensive and clear explanation on the importance of doing something to an individual or organisation would be the first step to change the attitude or perception thereby bringing the spirit of willingness to do it for the benefits stated or explained. This may help the partner organisations to appreciate and be committed to this new process of results-based reporting.

However, there is need to take into account of the organisation capacities which maybe at varying levels to adapt to results-based approaches. The inadequacy of support entails that most of the organisations especially CBOs may face a numerous challenges to adapt to Results-Based approaches due to organisational inadequate capacities. Therefore, there is need for donors/funders to increase the budget allocation to $\mathrm{M} \& \mathrm{E}$ activities, provide adequate data capturing tools, and also to providing tailor made orientations and trainings in the $M \& E$ processes considering the fact that organisations are at varying levels and also capacities. This would help to strengthen the $M$ \& E processes in the organisations being supported. 
Additionally, donors, network organisations and stakeholders should continue to provide comprehensive and clear explanation on the importance of M \& E/Result Based Management in the program so that partner organisations can appreciate and be committed to this new process of results-based reporting. It should be noted that although organisations appreciate the importance of $\mathrm{M} \& \mathrm{E}$ processes, low education levels among organisation members running the organisations or office bearers has remain a challenge to operationalise such processes. Interestingly the findings have also shown that organisations were provided with orientation in $\mathrm{M} \& \mathrm{E} / \mathrm{RBM}$ systems, reporting and financial management by donors as a support to strengthen the M \& E /Result Based Management systems. However, threequarters of the organisations indicated that support provided was not adequate, and therefore, it can be concluded that the support provided is not adequate.

From objective two, it can be summerised that $M \& E$ enhances decision making; ensures implementation of program according to plans; enhances transparency and accountability of resources to the donors and other stakeholders; enhances performance in results-based reporting; and also act as the resource mobilisation tools for the organisation. Notably there are weaknesses and problems in the $\mathrm{M} \& \mathrm{E}$ processes such as persistent lack of good and critical data. Although there are such weaknesses, there is a need for, donors and or other stakeholders and network organisations should continue to provide comprehensive and clear explanation on the importance of $M \& E$ E/Result Based Management in the program so that partner organisations can appreciate and be committed to this new process of results-based reporting.

In relation to the third research objective, it can be summerised that the major challenges which Member Organisations face in the M \& E processes included weak organisation capacity which mainly attributed to inadequate human resources, low education levels among organisation members, and lack of tailor made orientation in the $\mathrm{M} \& \mathrm{E}$ processes. The inadequacy of support entails that most of the organisations especially CBOs may face a numerous challenges to adapt to Results-Based approaches due to organisational inadequate capacities. Therefore, there is need for donors/funders to provide adequate data capturing tools, and also to providing tailor made orientations and trainings in the M \& E processes considering the fact that organisations are at varying levels and also capacities. This would help to strengthen the $\mathrm{M} \& \mathrm{E}$ processes in the organisations being supported.

Conclusively, the participants (member organisation) recommended that donors should provide tailor made orientation and trainings in $\mathrm{M} \& \mathrm{E}$ and report writing as well as technical support and guidance. The sharing of the data capturing tools to meet the reporting requirements was one of the recommendations which came out strongly from the organisations to the donors. On the other hand, there was common understanding that there is need to improve and strengthen the data collection process through the use of data capturing tools shared by the donors, and to establish the filing system and documentation of data, success stories and other important information collected during the project implementation. Finally there is need for organisation staff or members that attend the orientation and trainings in $\mathrm{M} \& \mathrm{E}$, report writing, financial and project management and other related trainings should orient other staff or members that did not attend the trainings or orientations.

\section{Recommendations}

Based on the research findings, the following recommendations have been considered to be of value and useful to various stakeholders of this research:-

1. There is need for donors and other stakeholders to continue providing a comprehensive and clear explanation on the importance of RBM to partner organisations. This may help the partner organisations to appreciate and be committed to this new process of results-based reporting.

2. Organisations appreciate the importance of $M \& E$ processes, however low education levels among organisation members running the organisations or office bearers has remain a challenge to operationalise such processes. Therefore, tailor made 
orientations and trainings in the $\mathrm{M}$ \& $\mathrm{E}$ processes considering the fact that organisations are at varying levels and capacities are needed. This would help to strengthen the M \& E processes in the organisations being supported.

3. The inadequacy of support entails that most of the organisations especially CBOs may face a numerous challenges to adapt to Results-Based approaches due to organisational inadequate capacities. Therefore, there is need for donors/funders to increase the budget allocation to $\mathrm{M} \& \mathrm{E}$ activities, provide adequate data capturing tools, and also to providing tailor made orientations and trainings in the $\mathrm{M} \& \mathrm{E}$ processes considering the fact that organisations are at varying levels and also capacities. This would help to strengthen the M \& E processes in the organisations being supported.

4. To the Member Organisations there is need to improve and strengthen the data collection process through the use of data capturing tools shared by the donors, and to establish the filing system and documentation of data, success stories and other important information collected during the project implementation. Finally there is need for organisation staff or members that attend the orientation and trainings in $M$ $\&$ E, report writing, financial and project management and other related trainings should orient other staff or members who did not attend the trainings or orientations.

\section{Conclusion}

From the findings it can be concluded that although organisations appreciate the importance of $\mathrm{M} \& \mathrm{E}$ processes, low education levels among organisation members running the organisations or office bearers has remain a challenge to operationalise such processes. Hence there is need for, donors, network organisations and stakeholders should continue to provide comprehensive and clear explanation on the importance of $\mathrm{M} \& \mathrm{E} / \mathrm{Result}$ Based Management in the program so that partner organisations can appreciate and be committed to this new process of results-based reporting.

Furthermore, although $\mathrm{M} \& \mathrm{E}$ processes have some weaknesses and problems such as persistent lack of good and critical data, $M$ \& E enhances decision making; ensures implementation of program according to plans; enhances transparency and accountability of resources to the donors and other stakeholders; enhances performance in results-based reporting; and also act as the resource mobilisation tools for the organisation.

It can also be concluded that that the major challenges which Member Organisations face in the $\mathrm{M} \& \mathrm{E}$ processes included weak organisation capacity which mainly attributed to inadequate human resources, low education levels among organisation members, and lack of tailor made orientation in the M \& E processes. The inadequacy of support entails that most of the organisations especially CBOs may face a numerous challenges to adapt to ResultsBased approaches due to organisational inadequate capacities. Therefore, there is need for donors/funders to increase the budget allocation to $\mathrm{M} \& \mathrm{E}$ activities, provide adequate data capturing tools, and also to providing tailor made orientations and trainings in the $\mathrm{M} \& \mathrm{E}$ processes considering the fact that organisations are at varying levels and also capacities.

Conclusively there is need for donors to provide tailor made orientation and trainings in $\mathrm{M}$ $\& \mathrm{E}$ and report writing; technical support and guidance; and increase budget allocation to $\mathrm{M}$ $\&$ E activities and also to employ the $\mathrm{M} \& \mathrm{E}$ Officer for project period. The sharing of the data capturing tools to meet the reporting requirements was one of the recommendations which came out strongly from the organisations to the donors. Furthermore, there is need for member for organisations to improve and strengthen the data collection process through the use of data capturing tools shared by the donors, and to establish the filing system and documentation of data, success stories and other important information collected during the project implementation. 
South American Journal of Management

Special Edition 2016

\section{Contribution to Knowledge}

The research findings of this study, have contributed significantly to the body of knowledge in the area of results based management and or monitoring and evaluation processes. As earlier stated M \& E enhances decision making; ensures implementation of program according to plans; transparency and accountability of resources to the donors and other stakeholders; value for money in relation to the performance in results-based reporting; and also act as the resource mobilisation tools for the organisation. It is from this background that results based management has become one of the conditionality's for funding.

However, there has been very few research studies if any at all that have been conducted before by other researchers in results based management especially in the area of the support which donors provide to the partner organisations to strengthen the results- based management. Furthermore, there is nothing much researched on the challenges which partner organisations face to adapt to results- based management which is new concept. This is further evident in the literature review which shows abstract or general challenges in the field of results- based management. Therefore, the findings of this research study has identified the support the support which donors provide to the partner organisations, and all the challenges which partner organisations face in the of results- based management. Already the findings have revealed that three quarters of the organisations which participated in the study indicated that the support is not adequate.

\section{Areas for Further Research}

In this study, the major weaknesses of the results based management were not adequately fully investigated. Therefore, there is need to undertake a research study to understand the weaknesses of RBM as a science which promote accountability, effectiveness and resource mobilisation tool. This may help the donors, research institutions, Monitoring and Evaluation Centres to strategies how such weaknesses can be mitigated and or addressed.

Another area of interest that needs to be considered is to investigate the approach which donors use to provide supports to partner organisations. This is a realisation that threequarters of the organisations indicated that support provided was not adequate. Hence another research study may provide recommendations how best the support approach could be refined.

\section{References}

[1.] Allen, T. Harrell, (1978) New Methods in Social Science Research: Praeger Publishers, New York [2.] Bailey, Kenneth D., (1978) “Methods of Social Research,” Ronald Press, New York,

[3.] Best, John W., and Kahn, James V. (1986), “Research in Education,” 5th Ed., Prentice-Hall of India Pvt. Ltd. New Delhi: India

[4.] Berg, B. L. (2007) Qualitative Research Methods for the Social Sciences, Pearson Education: Boston.

[5.] Binnendijk, A. (2000) Results-based Management in the Development Cooperation Agencies: A Review of Experience. Paper prepared for OECD/DAC Working Party on Aid Evaluation.

[6.] Booth, Wayne, Gregory G. Colomb and Joseph M. Williams (2008): The Craft of Research. Chicago, IL: University of Chicago Press

[7.] Coghlan, David and Teresa Brannick (2001): Doing Action Research in Your Own Organization. London: SAGE

[8.] Cochran, W. G. (1963) Sampling Techniques, 2nd Ed. John Wiley \& Sons, New York

[9.] Crawford P \& Bryce P. (2003): Project monitoring and evaluation: A method of enhancing the efficiency and effectiveness of aid project implementation. International Journal of Project Management, 21(5): 363-373, Elsevier Science Ltd and IPMA.

[10.] Danida (2005): Evaluation. Capacity Development, Outcome Evaluation, Field-testing of the Methodology. Available at: http://startinternational.org/library/archive/files/danida-cd-evaluation144_eab5be065b.pdf (accessed 18/05/2015). 
[11.] Ebrahim, A. (2003) Accountability in practice: mechanisms for NGOs, World Development, Vol 31, No. 5, pp: 813-829, www.elsevier.com/locate.worlddev.

[12.] Edwards, M. and Hulme, D. (2000) Scaling up NGO impact on development: learning from experience, In Development, NGOs and civil society, Edited by D. Eade, Oxfam, Oxford, pp 44- 63.

[13.] Ebrahim, Alnoor and V. Kasturi Rangan (2010): The Limits of Nonprofit Impact: A Contingency

Framework for Measuring Social Performance. Working paper, Available at: http://hbswk.hbs.edu/item/6439.html (accessed 23 May 2015)

[14.] Forss, K., Rebien, C. C. and, Carlsson, J (2002) Process Use of Evaluations: Type of Use that Precede Lessons Learned and Feedback, Evaluation, Vol. 8 (1): 29-45, Sage Publications: London, Thousand Oaks and New Delhi.

[15.] Hailey and Sorgenfrei (2004) Measuring success: Issues in Performance Measurement, Occasional Papers Series No. 44, INTRAC

[16.] IFRC (2011b): Project/programme monitoring and evaluation (M \& E) guide in NGOs programs. Geneva: IFRC

[17.] Kothari C.R, (2004) Research Methodology: Methods and Techniques $2^{\text {nd }}$ Ed. New Age International (P) Ltd., Publishers, New Delhi, India

[18.] Kusek, J.Z. and Rist, R. C. (2004) Ten Steps to a Results-Based Monitoring and Evaluation System, The World Bank: Washington DC.

[19.] McCoy L, Ngari P and Krumpe E. (2005): Building Monitoring, Evaluations and Reporting Systems for HIV/AIDS programmes. Washington DC. USAID

[20.] Mayne, John. (2007) Best Practices in Results-based Management: A Review of Experience. A Report for the United Nations Secretariat, Volume 1: Main Report. July.

[21.] Mayne, John (2007a); Challenges and lessonsin implementing Results-based Management, Evaluation Vol. 13, 2007

[22.] Meier, W. (2003) Results-Based Management: Towards a Common Understanding among Development Cooperation Agencies, Discussion Paper prepared for CIDA and DAC Working Party on Aid Effectiveness.

[23.] NORAD (2008): Results Management in Norwegian Development Cooperation: A practical guide. Oslo: Norwegian Agency for Development Cooperation NORAD)

[24.] NORAD (2013c): A Study of Monitoring and Evaluation in Six Norwegian Civil Society Organisations. Pdf Available at: http://www.norad.no/no/evaluering/publikasjoner/publikasjon?key=402245 (accessed 5/05/2015)

[25.] Organization for Economic Cooperation and Development (OECD), Development Assistance Committee - DAC (2002) Glossary and key terms in Evaluation and Results-based Management, OECD

[26.] Poate, D. (2012) Measuring and Managing Results: Lessons for Development Cooperation, UNDP: New York.

[27.] PASSIA (2004): Civil Society empowerment: Monitoring and Evaluation.

[28.] www.passia.org/seminars/2002/monitoring.htm (Accessed on 18/5/2015

[29.] Taylor, D., and Balloch, S. (2005) The Politics of Evaluation, The Policy Press: Bristol.

[30.] UNDP (2007) Evaluation of Results Based Management at UNDP: Achieving Results, Evaluation Office, UNDP: Now http://www.undp.org/eo/documents/thematic/RBM/RBM_Evaluation.pdf (Accessed on 20/06/2015)

[31.] UNDP (2001) Managing for Results: Monitoring and Evaluation in UNDP. http://stone.undp.org/undpweb/eo/evalnet/docstore3/yellowbook/documents/FrameWORKfinal.pdf (Accessed on 20/06/2015)

[32.] UNDP (2002) Handbook on Monitoring and Evaluation for Results, Evaluation Office, UNDP: New York.

[33.] Uitto JA. (2004): Multi-country co-operation around shared waters: Role of Monitoring and Evaluation. Global environmental change, 14(1): 5-14 